\title{
Learning with Older Adults through Intergenerational Service Learning in Physical Education Teacher Education
}

\author{
Pedro J. Ruiz-Montero ${ }^{1,2}$, Oscar Chiva-Bartoll ${ }^{3, *} \mathbb{*}$, Celina Salvador-García ${ }^{3,4} \oplus$ and \\ Cristian González-García ${ }^{2}$ \\ 1 Faculty of Education, University of Málaga, 29071 Málaga, Spain; pedrorumo@uma.es \\ 2 Department of Physical Education and Sport, Faculty of Education and Social Sciences, Campus of Melilla, \\ University of Granada, 52005 Melilla, Spain; cristiangg97@correo.ugr.es \\ 3 Department of Education; Faculty of Human and Social Sciences, University Jaume I, 12071 Castellón, Spain; \\ salvadoc@uji.es \\ 4 Faculty of Education, Universidad Internacional de la Rioja, 26006 Logroño, Spain \\ * Correspondence: ochiva@uji.es
}

Received: 7 January 2020; Accepted: 3 February 2020; Published: 5 February 2020

\begin{abstract}
Background: The population of older adults is growing faster but most of them experience physical, psychological, and social limitations. Higher education should reflect these concerns by providing students appropriate skills to support a sustainable society and putting the acquired theoretical knowledge into practice. Intergenerational Service Learning (SL) is an educational approach capable of contributing to these requirements. The goal of the study was to analyze the effects of an intergenerational SL program from the complementary perspective of the different agents involved. (2) Methods: The study used hermeneutic phenomenological methodology, widely used in educational research. A total of 23 (three female) Physical Education Teacher Education students (PETEs) and 20 older adults (three male) participated. Reflective journals were used for PETEs and semi-structured group interviews for older adults. (3) Results: The following categories emerged from PETEs: social sensitivity and disconfirmation of negative stereotypes, academic and professional learnings, satisfaction and personal growth, and desire for social justice. From older adults, four complementary categories emerged: disconfirmation of negative stereotypes, improvement of physical function, satisfaction and desire of continuity, and social interaction. (4) Conclusions: Intergenerational SL offers important social and educational inputs by deconstructing negative stereotypes and providing positive experiences to both PETEs and older adults.
\end{abstract}

Keywords: service learning; physical education teacher education; older adults; initial teacher training; health-care

\section{Introduction}

The population of older adults is growing faster and most of them experience an objective decrease in physical abilities that may be accompanied by psychological disorders and a loss of social and affective relationships [1]. This increase is often linked to a growing demand for long-term care. One in four older adults will spend time in a care home and the need for such care will persist [2]. Older adults are amongst the frailest in our population with high levels of physical dependency [3]. Regular physical activity limits the development and progression of chronic diseases and disabling conditions [4]. However, time spent in sedentary behavior has increased substantially over the last three decades [5] and it rises with age [6]. This could be lessened with the development of more intergenerational initiatives related to well-being, active aging, and physical and mental health in aged people [7]. 
Intergenerational experiences are often used in higher education to improve both disadvantaged older adults' quality of life together and students' understanding of aging [8]. Most relevant studies have reported that students who have more contact with older adults through friendship and volunteer experiences exhibit better attitudes toward working with older adults [9-12].

At this point, it is important to advise that higher education should increasingly reflect the needs, concerns, and intentions of society. That is, current higher education must strive to create the optimum conditions in which young people acquire the appropriate skills to support a sustainable society. A decade has just elapsed since Martha Nussbaum [13] referred to a 'silent crisis' in education, consisting of the progressive disappearance of civic and humanistic contents of the curricula. Consequently, today's higher education must not only provide the theoretical learning of personal, professional, and social competences, but also it should become a test bed to ensure the exercise of these ideals.

This educational renewal, focused on the promotion of active methodologies, finds in service learning (SL), an educational approach capable of contributing to the current training requirements. In this sense, on the threshold of the third millennium, Eyler and Giles [14] already pointed out that SL was a valid option to satisfy these approaches. Particularly, the competence-based approach to train Physical Education Teacher Education students (PETEs) encourages the implementation of SL, allowing students to apply learning in real conditions [15-17].

A widely accepted definition of SL defines it as a form of experiential education in which students engage in activities that address human and community needs together with structured opportunities for reflection designed to achieve desired learning outcomes [18]. It is a methodological approach that combines in-class material with volunteer-like services within the community, allowing students to learn the course's curriculum and apply it to real-life situations $[19,20]$. SL can be differentiated from other types of experiential education because it gives equal attention to both the service and learning components of the experience, as well as equal focus on benefits to both providers and recipients [21].

Previous studies have offered a panoramic overview of SL impact in terms of academic, professional, and social effects [22,23]. These results are also endorsed by many studies in the field of physical activity and sports sciences $[15,16,24,25]$. Therefore, SL may be useful for enabling students to understand and learn about aging and older adults. However, it is still necessary to provide more specific analyses in the particular context of older adults.

SL requires great effort and attention in the field of health-care promotion and community participation in intergenerational approaches. It is important to note that the American College of Sports Medicine highlights the need to have some basic knowledge in working with different collectives, while focusing on health promotion and community participation [26]. For this reason, it is necessary to study and be aware of the possibilities and insights of SL implemented with older adults, a population group that requires special attention.

Concerning the implementation of SL with older adults, Roodin et al. [27] presented a review of general literature focused on intergenerational SL. However, their approach is very wide and does not focus on the exact field of health-care and physical activity promotion. More specifically, according to the recent systematic review of Ruiz-Montero et al. [28], higher education SL has been used on a number of occasions for health-care and physical activity promotion among older adults, and to encourage community participation. The experiences of SL analyzed enabled both university students and older adults (to a lesser extent) to overcome stereotypes and biases to gain multigenerational perspectives, which triggered an improvement of mutual understanding and cohesion while favoring older adults' wellness.

According to this systematic review, the main topics investigated in this field may be classified into two dimensions: those relating to students, and those relating to older adults. On the one hand, some studies reported positive results in learning outcomes related to the students' personal perceptions, as well as the acquisition of professional skills [27], the knowledge of the consequences of aging among older adults [29], and the perceptions of professional cooperation [30]. On the other hand, outcomes focused on older adults are less studied and mainly address their general perceptions and 
satisfaction [31-34]. These results suggest that SL may be an optimal way to promote intergenerational social cohesion and promote older adults' health care $[35,36]$.

However, Roodlin, Brown and Shedlock [27], and Andreoletti and Howard [37] found that in most of the studies reporting benefits of intergenerational SL, the older adults' impact has not received the same degree of attention or concern in outcome evaluations. That is to say, while benefits are well documented for university students, fewer studies have deeply examined benefits for older adults. Thus, further research is needed to evaluate the global effects of SL programs, since many of the studies published in the field only analyze the perceptions and learning of one out of the two main agents involved. For this reason, this study aims to analyze the effects of an intergenerational SL program. This objective is approached from the complementary perspective of the different agents involved. Therefore, it is divided into two specific objectives; one related to knowing the effects on students and another considering the effects on older adults.

\section{Materials and Methods}

The study uses a qualitative method based on a hermeneutic phenomenological approach, following the guidelines for this type of educational research [38]. The objectives of this approach focus on the meaning of human experience (phenomenology) and on the understanding of actions in context (hermeneutics) [39]. In a phenomenological hermeneutical sense, the understanding of someone's experience depends on the human interpretation. Therefore, we can create comprehensive understanding, drawing on different perspectives concerning the analyzed events. Thus, considering the complementary viewpoints of the two main agents involved, this study raises the following research questions: "How did PETEs experience the effects of the intergenerational SL program?" and "How did older adults experience the effects of the intergenerational SL program?"

\subsection{Participants and Setting}

A total of 23 (three female) PETEs of the School of Education and Sports Sciences of Melilla (University of Granada) participated in this study. They belong to fifth year- "Assessment of the Physical Activity and Sports Teaching"-and third year- "Body Expression and Games" of the PETE program. The SL intervention was structured in two 40-minute weekly sessions and was 10 -weeks long. It took place during the first semester of the 2019/2020 academic year. To this end, the assisted living facility 'Gota de Leche', which is dedicated to serving groups of disadvantaged older people, collaborated.

The learning objectives set out in the intervention sessions always related to the two subjects involved in the present study, while the purpose of the service was to facilitate social inclusion and to improve general quality of life of disadvantaged or physical limited older adults. The 20 older adults (three male) involved in this study lived in the assisted living facility due to severe economic constraints or to physical and motor disabilities.

The intergenerational SL program was based on Kolb's learning stages [40]: concrete learning, reflective observation, abstract conceptualization, and active experimentation. Initially, a stage of concrete experience was carried out, focused on establishing the PETEs' initial contact with the older adults involved. After this phase, there was a stage of reflection and critical thinking in which the students focused on observation and reflection in order to contrast opinions and propose an action plan based on the subjects' content. The reflection also extended throughout the program by means of two systems: (1) group reflection guided by the professor after the practical sessions; and (2) individual reflection by writing a personal reflective journal. After making the first contact with the older adults' group and defining the needs to be met, the project required theoretically examining the topics and concepts of the subjects. This stage of abstract conceptualization allowed the students to design a specific intervention program based on adapted physical activity tasks including motor and cooperative games. The application of the program was the last stage, active experimentation, and after each session, new improvements and variations were proposed. 
The interventions were designed by the PETEs. In fact, the SL program consisted of designing and leading physical activity and motor game sessions. To create an effective SL experience, the guidelines and recommendations of Lamson et al. [19] and Nichols and Monard [41] were considered. The educators involved supervised the intervention proposals designed by the different groups of students on a weekly basis and before they were carried out. The contents worked during the intervention were linked to assessment instruments. They were related to physical and educational condition for fifth year subject, and types of games, rhythmic exercises, and body expression for third year subject. All sessions had the following standardized structure: 5 to $10 \mathrm{~min}$ of warm-up activities based on joint mobility, 25 to 35 min of physical fitness work through recreational games and corporal expression activities, and 5 to $10 \mathrm{~min}$ of cool-down activities focused on fostering social interaction among participants.

\subsection{Ethical Considerations}

To ensure fidelity and responsible investigation, the study followed established ethical considerations [42] and was approved by Ethical Committee of University of Granada ( $n^{\circ}$ 983/CEIH/2019). We tried to minimize researcher bias, however it should be clarified that one of the members of the research team participated as a teacher in the program. Before participating in the study, each student and older adult was informed of its purpose. Furthermore, written informed consent was obtained from all participants.

\subsection{Instruments}

The study used two different instruments for collecting information. On the one hand, reflective journals were used during and at the end of the program to understand the personal experiences of PETEs. Reflective journals are widely used in research practices in teacher training [43,44]. In this study, journals followed a semi-structured scheme, in which there were open questions to expose general perceptions and closed ones concerning more specific learnings. They were not graded in order to increase the honesty of the participants and avoid the fear of being judged [45]. On the other hand, three semi-structured group interviews were used in order to generate information in a natural and interactive way due to the diversity of the older adults' group. They lasted between 40 and $60 \mathrm{~min}$ each and were conducted at the end of the intervention by the same investigator. The interviews went from open questions referring to the global meaning of the program, such as: "What do you think about sharing this intergenerational experience with PETEs?", towards increasingly closed questions such as: "Has there been any remarkable effect of the program? Which one?" All participant older adults were given a voice. At all times it was a priority for the research team to make them feel comfortable [37].

\subsection{Analysis}

Data were analyzed employing a conceptual content analysis [46]. After the preparation phase, in which the units of analysis were selected, data were analyzed using an inductive approach. We used the N-Vivo qualitative analysis software (version 12) to carry out the process of reduction, categorization, and coding. As a result, we obtained a system of categories. In order to ensure reliability of results of the analysis, researchers' interpretations were based on participants' "voice", providing extracts from narratives in the text. In order to guarantee trustworthiness and credibility of the study, and to reduce the risk of bias, all researchers were involved in the analytic process, purified topics were thoroughly discussed, and the interpretations provided were based on quotations. Besides, we made sure that researcher bias did not skew the interpretation of what the participants said to fit a certain narrative by carrying out a member checking process, which consisted of granting the participants the opportunity to confirm their statements and make new contributions if they so desired. Finally, dependability was also considered, since an outside person reviewed the research process and the data analysis in order to ensure that the findings were consistent. Also, we presented enough information to repeat the study and obtain similar findings. 


\section{Results}

The results in this section are divided into the two complementary points of view of the SL experience. The first one refers to the emerging categories of PETEs experiences, and the second one refers to the emerging categories of disadvantaged older adults. We present and describe these categories building on representative quotes of their discourses and narratives to answer the research question based on the phenomenological analysis carried out.

\subsection{Physical Education Teacher Education Students' Categories}

In this first part, four emerging categories describe the principal effects and experiences lived by PETEs: social sensitivity and disconfirmation of negative stereotypes, academic and professional learnings, satisfaction and personal growth, and desire for social justice.

\subsubsection{Social Sensitivity and Disconfirmation of Negative Stereotypes}

Social sensitivity refers to the personal ability to perceive and understand the feelings and viewpoints of others. In our particular context, this category refers to the recognition and development of positive relationships between students and older adults. The intergenerational SL led the students to consider that they had experienced a positive change in their way of empathizing with the problems experienced by the older adults they worked with. This also refers to the ability to listen, understand, and discover qualities in others. The following quotations are representative of students' disconfirmation of negative stereotypes: "Older adults are not as I expected. They are in a very fragile situation, but they are normal people, wanting to feel good and do different things", and "On many occasions throughout the session I put myself in their shoes and I realize that in their situation I would think or act the same way (they do). Any of us may be in their same situation in a few years."

Furthermore, the students showed the importance of serving older adults on equal terms as an ethical and moral obligation that promotes inclusiveness. In fact, from their narratives, it is possible to ascertain the acceptance process and the recognition of everyone's value regardless of her diversity: "At the end of the day you realize that everyone is entitled to have a dignified aging process, no matter the age, culture, or sex. We all have the right to access to a dignified life."

PETEs also highlighted their surprise when discovering that older adults were fascinating, emphasizing what they actually have in common: "Some days they surprised me by telling us stories of their youth that I would have never imagined. In the end they are not so different from us. They are boxes full of surprises."

Thus, for the PETEs involved, the intergenerational SL has been a vital experience in the acquisition of deep levels of empathy towards older adults. Furthermore, students expressed disconfirmation of their negative stereotypes. Before the SL experience, some students thought that older people were conservative, boring, frail, and unhappy. But they discovered that these prejudices were wrong in many cases.

\subsubsection{Academic and Professional Learnings}

This category refers to those academic and professional skills which allow PETEs to achieve success on an educational and professional level. Most of the references of this category are related to the design and execution of Physical Education sessions. This refers to the ability to achieve objectives considering the deadlines, resources, and the service which has to be taken. The following quotations show this perspective: "Now that we are finishing the program, I start to realize that I have learned how to better focus the sessions, what kind of activities they like, which ones work best, etc." and "I am learning that if something does not go as planned, it is not necessarily a mistake, it is simply a matter of adapting what had been planned."

The reflections of the students showed the importance they give to different aspects such as the ability to plan and adapt physical exercises in order to develop their sessions successfully in the 
intergenerational SL. Similarly, the reflections and assessments they made regarding the need to be flexible in terms of organization and planning were clearly visible, improving their adaptative teaching capacity. These skills are key elements in the training of PETEs when planning learning based on a humanistic and inclusive viewpoint.

A second contribution that complements this category has to do with the ability to be persistent and perseverant with the tasks planned. This condition refers to the constant effort to achieve their initial objectives. In this vein, the following quotation is representative and shows the persistence capacity acquired by the PETEs: "One important lesson learned as a physical education teacher is the ability not to give up or get frustrated when something does not work-where there is a will, there is a way. The clue is to look for new perspectives when something does not work on the first attempt."

Thus, SL provides the experience of feeling how capacities such as organization, planning, persistence, and perseverance-which are constantly emphasized during the years of study-are essential when facing reality. For this reason, we can state that SL adds meaning to the theoretical and practical contents by means of its combination.

\subsubsection{Satisfaction and Personal Growth}

The personal growth category refers to the state whereby the individual has a feeling of satisfaction. Certainly, SL affects the personal welfare of the people who carry it out and these benefits have been reflected in the PETEs' discourse.

One of the nuances related to personal satisfaction referred by students is linked to increased self-esteem, which can be defined as the perception they have of themselves. In this regard, positive aspects were found in the analysis of their texts: "I feel good every time I finish the session. Although many activities do not go as planned, I feel I make them feel good. I mean, I know I can improve a little their lives."

This intergenerational SL created a feeling of self-improvement and personal satisfaction in PETEs because of the impact made on self and others social perception. This personal growth could also increase their confidence, as an educational value present in educational initiatives. This could make the teaching and learning processes less stressful, and promote educational environments of mutual help and reciprocal exchange: "The experience of applying what I planned and being able to adapt it during the session has made me gain confidence in my capacities. It's also been a satisfying experience for most of the classmates I talk to."

These kind of comments show that spending time helping other people, improves students' confidence, which leads them to grow both personally and socially. This fact endorses the positive impact of intergenerational SL in the prevention of aversive situations in disadvantaged populations as older adults.

\subsubsection{Desire for Social Justice}

The last category for students deals with their personal disposition and desire to improve social justice and promote sustainable human development. This category refers to the willingness to focus on, and encourage, respectful habits towards everyone who is around us, as well as to foster acts of rebellion in the face of injustices. It can be observed that intergenerational SL has helped PETEs to awaken critical thinking, and a rebellious attitude in the face of injustices. From their narratives, we can interpret that experiencing real situations undoubtedly has a great impact on them. Students refer to this attitude in their journals: "Anyone could be in their situation in a few years. It is very unfair that most people turn their back on elderly. They are not to blame for not being completely independent."

Students' voices raise the issue of educational reinvention, seeing it as an essential key to overcoming any obstacle that prevents the best learning. It is about promoting a stimulating atmosphere of cooperation that responds to the personal and community learning needs of all, without any exception. Besides, in this category, also emerges a natural disposition of PETEs to help people without the need to receive anything in return. The following quotations are representative: "We all 
should understand that sometimes it is necessary to help people who need it without expecting anything in return. It is not always necessary to spend money to help, we can contribute in many ways, such as this one."

This intergenerational SL has promoted PETEs values such as generosity, altruism, and caring for others, among many others. Through real contact with disadvantaged older adults, they have been able to grow these values in a real way, rather than through theoretical explanations in the classroom.

Finally, a new expression of this category refers to the advantages to cooperate intra-group to the proper functioning of the service provided: "Collaborating as a team has allowed us to move forward in many activities. When someone did not see the solution to a problem there was always someone who brought in a new vision or new knowledge. In this sense, working as a team has allowed us to optimize the time and resources available."

These words reflect how a joint action allowed them to carry out their interventions successfully on numerous occasions. Joining efforts and capacities allowed them to contribute in a more satisfactory way to the integral well-being of disadvantaged older adults.

\subsection{Older Adults' Categories}

Regarding the results obtained from the semi-structured group interviews conducted to disadvantaged older adults, the following four categories emerged: disconfirmation of negative stereotypes, improvement of physical function, satisfaction and desire of continuity, and social interaction.

\subsubsection{Disconfirmation of Negative Stereotypes}

A stereotype is defined as a generalized belief generating expectations that people might have about every person of a particular group. Stereotypes towards youth lead to social categorization and may arise for a number of reasons. Some of the negative stereotypes generally attributed to youth are that they are lazy, disrespectful, revealing, and selfish people. However, after this intergenerational SL program, the majority of older adults conveyed that the experience had a positive effect on their views of college students. The most common comment was the good impression the experience made on them by youth. A representative quotation of this topic was: "I did not expect them to treat us so well, nor would they have such interest in our well-being."

The intergenerational SL helped them recognize how considerate, and polite the students who worked with them were. As some older adults stated: "A lot of people criticize youth ... they say they are rude and inconsiderate but that is a misconception", or "They have been very polite with us, we are very happy to have spent time with them. It would be great if more students came and worked with us."

In this sense, the older adults also came to empathize and understand that young students were not so different from themselves on essential attitudes towards life. "Youth is not as many people believe. In the end they just want to succeed and be happy, like we all did when we were their age." Therefore, in a way, there was a personal approach that led older adults to certainly recognize college students as equals in essence.

Thus, in the case of older adults, we can also observe how the intergenerational experience lived, based on the interaction and personal contact with PETEs in the SL program, promoted the disconfirmation of previous negative stereotypes.

\subsubsection{Improvement of Physical Function}

Older adults showed great satisfaction with the effectiveness of the program in terms of physical function. This is associated with outcomes related to the level of limitation in performing activities such as self-care, walking, climbing stairs, bending down, catching or carrying weights.

The maintenance of overall functioning is essential for aging individuals in order to remain independent, prevent the development of various diseases and chronic illnesses, reduce the risk of fall-induced injuries, and increase overall mood and satisfaction with life. In this vein, they mainly refer to the improvement of two basic issues: walking and vitality. 
With regard to walking, there are very eloquent quotes about their improvement, such as the following ones: "It's as if I had learned to walk again because I couldn't walk properly before they came", or "I couldn't quite walk because I have a paralysis since I was a little girl, so I left my house and left everything. Lately, by doing these activities I have improved a bit", or this one referring to the joy they felt when young students arrived: "It helped me to strengthen the whole body. I'm very old, I enjoyed the moment they arrived every morning."

On the other hand, in relation to the increase of their vitalism and vigor, very representative quotations also emerged: "I have more vitality than before, I feel strong, I feel it in my hands." Other eloquent quotes that support this category are: "Every day I would like to do more things, but generally I didn't decide to do anything at all. However, after exercising I feel more active wanting to do more things", and: "After this season I notice that I eat more, walk more, and sleep better ..."

In short, from these results, it can be interpreted that the intergenerational SL program was effective in relation to the improvement of the physical function, thus materializing one of the fundamental pillars that motivated the implementation of the PETEs program.

\subsubsection{Satisfaction and Desire of Continuity}

Disadvantaged older adults' comments also alluded to their satisfaction and desire of continuity of the SL program, with most of them agreed that it should have lasted longer. This is a clear sign that they were satisfied with the work and interaction with PETEs. In fact, they were disgusted at the end of the intergenerational program.

Among the large number of comments regarding this issue, some of the following stand out for their representativeness: "When I was told that the program was over, I felt bad because we were doing very distracted games ... It seems that I feel a little better and now I fear getting worse again." In this comment, as well as in some others that we will see next, the feeling of sadness that generated the completion of the SL program is evident.

Some other references that show how older adults felt are: "I was happy all this time and then, when they stopped coming, it came with a bit of sadness to me", or "I wish they kept coming, I am glad that young people came to work with us, I wish they came every day", or directly: "I miss them for the joy they brought to our lives."

This fact should make us seriously reflect on the duration and completion of this intergenerational SL program in future editions. As the results show, the way we complete the program is something that needs to be improved, since it seems inappropriate to leave the group of older adults with such feeling of sadness and loneliness.

\subsubsection{Social Interaction}

Finally, another category that emerged from the discourse of older adults referred to social interaction. This element was another component of the intergenerational SL program that contributed to improving the quality of life of disadvantaged older adults. When noticing the strengths of the program, some older adults commented that interaction with PETEs helped them escape from their daily concerns.

Some of the quotes that best exemplify this issue are: "The activities came in handy for my legs and hands, but also for my head as they helped me not to think about my daily concerns", or "When I'm in class I forget about sadness and pain."

In this vein, a common topic was bringing the generations together. There are recurring allusions to conversations and oral communication maintained during the sessions between the young students and the older adults: "We have talked more than we talked on a normal day. In addition, we have had the possibility of interacting with young people, which is almost impossible here."

This contact and social interaction helped older adults fight against boredom: "When students come we exercise, talk and don't spend all our time without moving. We are less bored since the only contact with young people we have here is with the facility workers." In fact, these comments suggest that boredom 
is a circumstance that significantly worsens the quality of life of many older adults. They express this that clear: "Boredom is one of the things that hurts most, but if you talk and get distracted, you feel better."

This category lets us have an idea of the importance of the program in social terms. That is, the mere contact and social interaction between participants (servers and served) gives the program meaning and value. These results suggest that although both groups are experiencing different stages of life, it does not necessarily render them socially incompatible.

\section{Discussion}

The main objective of this study was to describe the impact that the intergenerational SL program implemented had from the complementary perspective of the two agents involved: PETEs and older adults. Based on the results of the hermeneutical phenomenological analysis carried out, Table 1 shows the categories obtained from the two groups, displayed in parallel in order to highlight their complementarity.

Table 1. Complementary intergenerational service-learning experiences.

\begin{tabular}{cc}
\hline Physical Education Teacher Education Students & Disadvantaged Older Adults \\
\hline Social sensitivity and disconfirmation of negative stereotypes & Disconfirmation of negative stereotypes \\
\hline Academic and professional learning & Improvement of physical function \\
\hline Satisfaction and personal growth & Satisfaction and desire of continuity \\
\hline Desire for social justice & - \\
\hline- & Social interaction \\
\hline
\end{tabular}

All in all, these complementary results illustrate how intergenerational SL can provide benefits to both PETEs and disadvantaged older adults, and is fundamental for developing intergenerational understanding. Below, we discuss the results as set out in Table 1, with the intention of emphasizing the complementarity between both perspectives.

From this comprehensive approach, there is an evident connection between the category 'social sensitivity and disconfirmation of negative stereotypes' reported by the students, with that of 'disconfirmation of negative stereotypes' of older adults. Therefore, these results indicate that negative stereotypes were deconstructed by both groups. In previous SL studies, students have reported gains in understanding of challenges and in empathy with the vulnerable populations they served [10,11,47-49]. In this regard, according to various studies, SL represents an appropriate setting for acquiring social comprehension of vulnerable collectives $[16,49,50]$. Our outcomes show that the interaction based on the need to solve real situations helped PETEs to broaden their conception and awareness of the reality of disadvantaged older adults, thus overcoming many predetermined stereotypes caused by the lack of positive contact with them [51-54]. Specifically, according to these results, we can suggest that familiarizing students with a more realistic and personalized view of aging decreased negative attitudes towards older adults, in line with Augustin and Freshman [55]; debunking negative stereotypes, and increasing student knowledge of the structure and operations of organizations providing services to older adults [56]. On the other hand, regarding the disconfirmation of negative stereotypes of older adults, our results also support that intergenerational SL contributes to changing the vision that older adults have of young people, which is in line with the results reported by Ruiz-Montero et al. [28] in their systematic review of the literature.

In the same vein, the category 'satisfaction and personal growth', emerged from PETEs, looks closely related to that of 'satisfaction and desire of continuity', of older adults, since both represent the satisfaction and positive experience of each group. The results related to the satisfaction and personal growth in PETEs reveal that there was a reformulation of values and beliefs about their way of relating to others, coinciding with previous analysis of narratives about experiential learning in Physical Education [57]. Moreover, we also found coincidences in relation to the change in attitudes about 
oneself [58], and about increasing self-confidence through SL [59,60]. Concerning the 'satisfaction and desire of continuity' of older adults, previous research is consistent with our results [31-34]. In fact, this is one of the most common results in published studies on intergenerational SL programs [28].

The complementarity between the categories 'academic and professional learnings' and 'improvement of physical function', can be established since they seem to reflect the same reality from both perspectives (servers and receivers of the same service). In relation to the effectiveness of the program in these terms, our results coincide with those of previous studies. On the one hand, regarding the academic and professional learning of PETEs, the content analysis showed that the PETEs acquired useful abilities for their professional future. PETEs referred to improvements in the capacity to solve difficulties in situ and adapt physical activities to the older adults. These results are in accordance with the effects of SL [23], as well as with two meta-analyses in relation to overall improvements in the academic setting $[22,58]$. This fact, in turn, shows that the SL experience led the PETEs to apply the previously acquired content, interweaving theoretical and practical knowledge $[50,60]$. On the other hand, when it comes to the improvement of the physical function perceived by older adults, the improvement of several related issues, such as pain, mobility problems, weakness, or sadness, were reported in our group interviews [61]. In this sense, the physical activity sessions generated an improvement in the older adults perceived physical function, according to a large number of studies that recognize physical activity's key role to preserving physical functioning for performing daily life activities [62-65].

Concerning the 'desire for social justice' category reported by the PETEs, at first sight it does not seem directly associated with the category 'social interaction' reported by older adults. However, it is not unreasonable to predict that precisely from the social interaction experienced emerged that demand for social justice on the part of the students. In the category 'desire for social justice' expressed by PETEs, the results indicate that SL contributed to making students aware of the fact that social justice still represents an unmet goal. These results show the possibilities of intergenerational SL as an educational initiative capable of raising social consciousness, being consistent with recent studies that report effects related to the development of a social conscience and the comprehension of community problems after the application of SL in the Physical Education area [57]. In this case, the reflection processes implemented might have played a crucial role, as suggested in previous research [45]. On the other hand, regarding the 'social interaction' category emerged from older adults' interviews, it is important to note that the beneficial outcomes are based on the positive engagement created from the interaction between older adults and PETEs [32]. In the same line, Zucchero [8], in the analysis of a similar intergenerational SL experience, reported an improvement in mutual relationship formation and positive experiences in the group of older adults. These results clearly show that SL may be an optimal way to promote intergenerational social cohesion and promote older adults' well-being [35,36].

Finally, before drawing conclusions of this study, it is important to mention that one of the biggest limitations of this research was that older adults were originally hesitant to participate in the study because they were not sure what the program would be like and they did not want to commit to participating in all the sessions. However, we emphasized that it was completely voluntary, since we did not want to exclude anyone from participating. On the other hand, there is no question that integrating intergenerational SL into a course requires extra time and commitment on the part of both, students and professors [66].

\section{Conclusions}

In conclusion, humanity becomes gradually aged and the need for young people educated in the requirements of our aging population continues to grow. Experiences of intergenerational SL like the one studied here offer an important service by giving disadvantaged older adults an opportunity to engage with younger students of their nearby community. Such social engagement may deconstruct negative stereotypes and increase feelings of successful aging in older adults while students can benefit 
by improving their academic and professional learning and by being more socially engaged and aware of the lives and diversity of disadvantaged populations.

Regarding future research, we suggest two recommendations. First, for improving data collection with older adults it is important to take enough time to explain them the importance and implications of this kind of intergenerational SL. Older adults will be more likely to participate if they understand the program's benefits for all participants involved. Second, although it requires more time, we highly recommend older adults' data to be collected not only at the end but also during the SL program. That would help researchers to better understand the meaning of the experience from the older adults' point of view.

Author Contributions: Conceptualization, P.J.R.-M. and O.C.-B.; Data curation, P.J.R.-M., O.C.-B. and C.S.-G.; Formal analysis, P.J.R.-M. and O.C.-B.; Funding acquisition, P.J.R.-M. and O.C.-B.; Investigation, P.J.R.-M., O.C.-B., C.S.-G. and C.G.-G.; Methodology, P.J.R.-M. and O.C.-B.; Resources, O.C.-B. and C.G.-G.; Software, C.S.-G. and C.G.-G.; Supervision, C.S.-G., P.J.R.-M. and O.C.-B.; Writing-original draft, P.J.R.-M. and O.C.-B.; Writing-review \& editing, C.S.-G. and C.G.-G. All authors have resd and agreed to the published version of the manuscript.

Funding: This research was funded by (1) UJI- A2019-01", (2) University of Granada, Plan FIDO 2018, Quality and Innovation Unit, project n ${ }^{\circ} 572$, and (3), Scholarship to CGG, Initiation in Research by Vice-Rector's Office for Scientific Policy and Research, UGR.

Acknowledgments: We would like to thank all the older adults and students who participated in this study. Thanks as well to the assisted living facility 'Gota de Leche' of Melilla. Finally, we would like to thank the professional translator that assisted us in the translation process of the text and the quotes.

Conflicts of Interest: The authors declare no conflict of interest. The funders had no role in the design of the study; in the collection, analyses, or interpretation of data; in the writing of the manuscript, or in the decision to publish the results.

\section{References}

1. Hsu, W.H.; Chen, C.L.; Kuo, L.T.; Fan, C.H.; Lee, M.S.; Hsu, R.W.W. The relationship between health-related fitness and quality of life in postmenopausal women from Southern Taiwan. Clin. Interv. Aging 2014, 9 , 1573-1579. [CrossRef]

2. Harwood, R.H. Do we still need care homes? Age Ageing 2004, 33, 529-530. [CrossRef]

3. Gordon, A.L.; Franklin, M.; Bradshaw, L.; Logan, P.; Elliott, R.; Gladman, J.R. Health status of UK care home residents: A cohort study. Age Ageing 2014, 43, 97-103. [CrossRef]

4. World Health Organization. Global Recommendations on Physical Activity for Health; World Health Organization: Geneva, Switzerland, 2010; Available online: http://apps.who.int/iris/bitstream/handle/ 10665/44399/9789241599979_eng.pdf?sequence=1 (accessed on 30 December 2019).

5. Van Der Ploeg, H.P.; Venugopal, K.; Chau, J.Y.; van Poppel, M.N.; Breedveld, K.; Merom, D.; Bauman, A.E. Non-occupational sedentary behaviors: Population changes in The Netherlands, 1975-2005. Am. J. Prev. Med. 2013, 44, 382-387. [CrossRef] [PubMed]

6. Bellettiere, J.; Carlson, J.A.; Rosenberg, D.; Singhania, A.; Natarajan, L.; Berardi, V.; LaCroix, A.Z.; Sears, D.D.; Moran, K.; Crist, K.; et al. Gender and Age Differences in Hourly and Daily Patterns of Sedentary Time in Older Adults Living in Retirement Communities. PLoS ONE 2015, 10, e0136161. [CrossRef] [PubMed]

7. Horowitz, B.P.; Wong, S.D.; Dechello, K. Intergenerational Service Learning: To Promote Active Aging, and Occupational Therapy Gerontology Practice. Gerontol. Geriatr. Educ. 2010, 31, 375-391. [CrossRef] [PubMed]

8. Zucchero, R.A. Share Your Experience and I'll Lend You My Ear: Older Adult Outcomes of an Intergenerational Service-Learning Experience. Gerontol. Geriatr. Educ. 2010, 31, 3383-3402. [CrossRef]

9. Chen, S.Y. The effectiveness of elder hostel learning model on active aging. J. Health Prom. Health Educ. 2010, 33, 91-114.

10. Dorfman, L.T.; Murty, S.; Ingram, J.G.; Evans, R.J. Incorporating intergenerational service-learning into an introductory gerontology course. J. Gerontol. Soc. Work 2002, 39, 219-240. [CrossRef]

11. Gutheil, I.A.; Chernesky, R.H.; Sherratt, M. Influencing student attitudes toward older adults: Results of a service-learning collaboration. Educ. Gerontol. 2006, 32, 771-784. [CrossRef]

12. Van Dussen, D.J.; Weaver, R.R. Undergraduate students' perceptions and behaviors related to the aged and to aging processes. Educ. Gerontol. 2009, 35, 342-357. [CrossRef] 
13. Nussbaum, M. Sin Fines de Lucro. Por qué la Democracia Necesita las Humanidades; Katz: Buenos Aires, Argentina, 2010.

14. Eyler, J.S.; Giles, D.E. Where's the Learning in Service-Learning; Jossey Bass: San Francisco, CA, USA, 1999.

15. Carson, R.L.; Raguse, A.L. Systematic review of service-learning in youth physical activity settings. Quest 2014, 66, 57-95. [CrossRef]

16. Cervantes, C.M.; Meaney, K.S. Examining service-learning literature in physical education teacher education: Recommendations for practice and research. Quest 2013, 65, 332-353. [CrossRef]

17. Capella-Peris, C.; Gil-Gómez, J.; Chiva-Bartoll, Ò. Innovative analysis of service-learning effects in physical education: A mixed-methods approach. J. Teach. Phys. Educ. 2019, 39, 102-110. [CrossRef]

18. Jacoby, B. Service-Learning in Higher Education: Concepts and Practices; Jossey-Bass: San Francisco, CA, USA, 1996.

19. Lamson, A.; Ballard, S.M.; LaClaire, S. Creating an effective intergenerational service-learning experience: Components of the UGIVE Program. J. Teach. Marriage Fam. 2006, 6, 186-205.

20. Yorio, P.L.; Ye, F. A meta-analysis on the effects of service-learning on the social, personal, and cognitive outcomes of learning. Acad. Manag. Learn. Educ. 2012, 11, 9-27. [CrossRef]

21. Furco, A. Service-learning: A balanced approach to experiential education. In Expanding Boundaries: Service and Learning; Taylor, A., Ed.; Corporation for National Service: Washington, DC, USA, 1996; pp. 2-6.

22. Conway, J.M.; Amel, E.L.; Gerwien, D.P. Teaching and Learning in the Social Context: A Meta-Analysis of Service Learning's Effects on Academic, Personal, Social, and Citizenship Outcomes. Teach. Psychol. 2009, 36, 233-245. [CrossRef]

23. Warren, J.L. Does Service-Learning Increase Student Learning? A Meta-Analysis. Mich. J. Community Serv. Learn. 2012, 18, 56-61.

24. Chiva-Bartoll, O.; Capella-Peris, C.; Salvador-Garcia, C. Service-Learning in Physical Education Teacher Education: Towards a Critical and Inclusive Perspective. J. Educ. Teach. 2020, 46, Forthcoming.

25. Chiva-Bartoll, O.; Ruiz-Montero, P.J.; Martin Moya, R.; Pérez López, I.J.; Giles Girela, J.; Garcia Suarez, J.; Rivera García, E. University Service-Learning in Physical Education and Sport Sciences: A systematic review. Rev. Complut. Educ. 2019, 30, 1147-1164. [CrossRef]

26. Nelson, M.E.; Rejeski, W.J.; Blair, S.N.; Duncan, P.W.; Judge, J.O.; King, A.C.; Castaneda-Sceppa, C. Physical activity and public health in older adults-Recommendation from the American college of sports medicine and the American heart association. Circulation 2007, 116, 1094-1105. [CrossRef] [PubMed]

27. Roodin, P.; Brown, L.H.; Shedlock, D. Intergenerational Service-Learning: A Review of Recent Literature and Directions for the Future. Gerontol. Geriatr. Educ. 2013, 34, 3-25. [CrossRef] [PubMed]

28. Ruiz-Montero, P.J.; Chiva-Bartoll, O.; Salvador-García, C.; Martín-Moya, R. Service-Learning with College Students toward Health-Care of Older Adults: A Systematic Review. Int. J. Environ. Res. Public Health 2019, 16, 4497. [CrossRef]

29. Kolb, P. Interest of racially and ethnically diverse social work students in gerontological social work. Educ. Gerontol. 2008, 34, 907-922. [CrossRef]

30. Neill, M.; Hayward, K.S.; Peterson, T. Students' perceptions of the interprofessional team in practice through the application of servant leadership principles. J. Interprof. Care 2007, 21, 425-432. [CrossRef] [PubMed]

31. Hegeman, C.R.; Roodin, P.; Gilliland, K.A.; Ó'Flathabháin, K.B. Intergenerational service learning: Linking three generations: Concept, history, and outcome assessment. Gerontol. Geriatr. Educ. 2010, 31, 37-54. [CrossRef]

32. Lynch, C.; Stein, L.A.; Grimshaw, S.; Doyle, E.; Camberg, L.; Ben-Ur, E. The impacts of service learning on students and community members: Lessons from design projects for older adults. In Proceedings of the IEEE Frontiers in Education Conference (FIE), Madrid, Spain, 22-25 October 2014; FIE: Jacksonm, MI, USA, 2014; pp. 1-9.

33. Underwood, H.L.; Dorfman, L.T. A view from the other side: Elders' reactions to intergenerational service-learning. J. Intergener. Relatsh. 2006, 4, 43-60. [CrossRef]

34. Krout, J.A.; Bergman, E.; Bianconi, P.; Caldwell, K.; Dorsey, J.; Durnford, S.; Erickson, M.A.; Lapp, J.; Monroe, J.E.; Pogorzala, C.; et al. Intergenerational service learning with elders: Multidisciplinary activities and outcomes. Gerontol. Geriatr. Educ. 2010, 31, 55-74. [CrossRef] 
35. Bunting, S.R.; Lax, G.A. Program Profile: A Service-Learning Model for Intergenerational Conversation about Science and Current Events between Longterm Care Residents and University Students: Case Study. J. Intergener. Relatsh. 2019, 17, 234-249. [CrossRef]

36. Heuer, S.; Douglas, N.; Burney, T.; Willer, R. Service-learning with older adults in care communities: Measures of attitude shifts in undergraduate students. Gerontol. Geriatr. Educ. 2019, 1-14. [CrossRef]

37. Andreoletti, C.; Howard, J.L. Bridging the generation gap: Intergenerational service-learning benefits young and old. Gerontol. Geriatr. Educ. 2016, 39, 46-60. [CrossRef] [PubMed]

38. Barnacle, R. Reflection on lived experience in educational research. Educ. Philos. Theory 2004, 36, 57-67. [CrossRef]

39. Smith, J.A. Interpretative phenomenological analysis in sport and exercise: Getting at experience. In Routledge Handbook of Qualitative Research in Sport and Exercise; Smith, B., Sparkes, A.C., Eds.; Routledge: London, UK, 2016; pp. 41-251.

40. Kolb, D. Experiential Learning: Experience as the Source of Learning and Development; Prentice Hall: Englewood Cliffs, NJ, USA, 1984.

41. Nichols, A.; Monard, A. Designing intergenerational service-learning courses based on student characteristics. Educ. Gerontol. 2001, 27, 37-48. [CrossRef]

42. American Psychological Association. Publication Manual of the American Psychological Association, 6th ed.; American Psychological Association: Washington, DC, USA, 2010.

43. Kugelmass, J.W. Subjective experience and the preparation of activist teachers: Confronting the mean old snapping turtle and the great big bear. Teach. Teach. Educ. 2000, 16, 179-194. [CrossRef]

44. Nolan, A. Encouraging the reflection process in undergraduate teachers using guided reflection. Australas. J. Early Child. 2008, 33, 31-36. [CrossRef]

45. Schmidt, N.A.; Brown, J.M. Service learning in undergraduate nursing education: Strategies to facilitate meaningful reflection. J. Prof. Nurs. 2016, 32, 100-106. [CrossRef]

46. Kulatunga, U.; Amaratunga, R.D.G.; Haigh, R.P. Structuring the Unstructured Data: The Use of Content Analysis. 2007. Available online: http://usir.salford.ac.uk/9857/ (accessed on 30 December 2019).

47. Brown, A.; Roodin, L. Service-learning in gerontology: An out-of-classroom experience. Educ. Gerontol. 2001, 27, 89-103. [CrossRef]

48. Cohen, H.L.; Hatchett, B.; Eastridge, D. Intergenerational service-learning: An innovative teaching strategy to infuse gerontology content into foundation courses. J. Gerontol. Soc. Work 2006, 48, 161-178. [CrossRef]

49. Peacock, J.R.; Flythe, M.K.; Jones, K. A service-learning collaboration: A graduate gerontology program and a foster grandparent program. Educ. Gerontol. 2006, 32, 335-349. [CrossRef]

50. Galvan, C.; Parker, M. Investigating the reciprocal nature of service-learning in physical education teacher education. J. Exp. Educ. 2011, 34, 55-70. [CrossRef]

51. Gil-Gómez, J.; Chiva-Bartoll, Ó.; Martí-Puig, M. The impact of service learning on the training of pre-service teachers: Analysis from a physical education subject. Eur. Phys. Educ. Rev. 2015, 21, 467-484. [CrossRef]

52. Frenchs, P.M.; Mosher-Ashley, E. College students' attitudes toward residential care facilities. Educ. Gerontol. 2000, 26, 583-603. [CrossRef]

53. Kimuna, S.R.; Knox, D.; Zusman, M. College students' perceptions about older people and aging. Educ. Gerontol. 2005, 31, 563-572. [CrossRef]

54. Lee, Y.S. Measures of student attitudes on aging. Educ. Gerontol. 2009, 35, 121-134. [CrossRef]

55. Augustin, F.; Freshman, B. The effects of service-learning on college students' attitudes toward older adults. Gerontol. Geriatr. Educ. 2015, 37, 123-144. [CrossRef]

56. Jones, S.H. Life is experienced until we die: Effects of service-learning on gerontology competencies and attitudes toward aging. Adv. Soc. Work 2011, 12, 94-112. [CrossRef]

57. Whitley, M.A.; Walsh, D.; Hayden, L.; Gould, D. Narratives of experiential learning: Students' engagement in a physical activity-based service-learning course. J. Teach. Phys. Educ. 2017, 36, 419-429. [CrossRef]

58. Celio, C.I.; Durlak, J.; Dymnicki, A. A meta-analysis of the impact of service-learning on students. J. Exp. Educ. 2011, 34, 164-181. [CrossRef]

59. Carrington, S.; Saggers, B. Service-learning informing the development of an inclusive ethical framework for beginning teachers. Teach. Teach. Educ. 2008, 24, 795-806. [CrossRef]

60. Chambers, D.J.; Lavery, S. Service-learning: A valuable component of pre-service teacher education. Aust. J. Teach. Educ. 2012, 37, 128-137. [CrossRef] 
61. Moschny, A.; Platen, P.; Klaassen-Mielke, R.; Trampisch, U.; Hinrichs, T. Barriers to physical activity in older adults in Germany: A cross-sectional study. Int. J. Behav. Nutr. Phys. Act. 2011, 8, 121. [CrossRef] [PubMed]

62. Merellano-Navarro, E.; Collado-Mateo, D.; García-Rubio, J.; Gusi, N.; Olivares, P.R. Validity of the International Fitness Scale "IFIS" in older adults. Exp. Gerontol. 2017, 95, 77-81. [CrossRef] [PubMed]

63. Milanović, Z.; Pantelić, S.; Trajković, N.; Sporiš, G.; Kostić, R.; James, N. Age-related decrease in physical activity and functional fitness among elderly men and women. Clin. Interv. Aging 2013, 8, 549-556. [CrossRef] [PubMed]

64. Toraman, N.F.; Erman, A.; Agyar, E. Effects of multicomponent training on functional fitness in older adults. J. Aging Phys. Act. 2004, 12, 538-553. [CrossRef] [PubMed]

65. Vagetti, G.C.; Barbosa Filho, V.C.; Moreira, N.B.; Oliveira, V.D.; Mazzardo, O.; Campos, W.D. Association between physical activity and quality of life in the elderly: A systematic review, 2000-2012. Braz. J. Psychiatry 2014, 36, 76-88. [CrossRef]

66. Karasik, R.J. Breaking the time barrier: Helping students "find the time" to do intergenerational service-learning. Gerontol. Geriatr. Educ. 2005, 25, 49-63. [CrossRef]

(C) 2020 by the authors. Licensee MDPI, Basel, Switzerland. This article is an open access article distributed under the terms and conditions of the Creative Commons Attribution (CC BY) license (http://creativecommons.org/licenses/by/4.0/). 